\title{
COMPARATIVE ANALYSIS OF BUCKLING CRITERIA FOR ENGINEERING STRUCTURES. MULTI-DEGREE SYSTEM
}

\author{
Leonid Yulianovich Stupishin* Marya Leonidovna Moshkevich \\ Southwest State University, Kursk, Russia
}

The criteria of the buckling of engineering structures in terms of the systems with lumped parameters are discussed in the article. The examples of setting buckling problems and their solutions using Timoshenko and Bryan criteria's, and the criterion of the critical levels of energy are given. The analysis of the compared approaches, their strengths and shortcomings in terms of the multi-degree systems are presented.

Key words: Buckling, Timoshenko criteria, Bryan criteria, Criterion of the critical levels of energy, Multi-degree systems, Systems with lumped parameters

\section{INTRODUCTION}

The buckling is one of the most important limit states, which received much attention over the hundred years. However, there is still no consensus on the causes of its manifestations and, accordingly, its criteria for characterizing [01-09]. The most popular among the engineers and researchers of energy criteria are two generally accepted formulations: the buckling criterion in the form of Timoshenko [01], and the buckling criterion in the form of Bryan [02]. But it is difficult to argue that these approaches allow us to investigate the entire spectrum of tasks caused of structures buckling. One alternative could be a variation criterion of the critical energy levels proposed in [08]. Below is a comparative analysis of these approaches to the buckling of engineering structures investigations with a simple example of a system with one degree of freedom.

Consider elastically deformable system exposed to contraction shown in Figure 1. The proposed schema differs from the classical Timoshenko's, that it describes the initial stage of deformation - contraction of the rod, at which the accumulation of strain energy. It is necessary to describe the behavior of the system, according to the ideas of Brian. Therefore, for the joint we have formally two degrees of freedom: the longitudinal movement and rotation due to the loss of initial state. However, to describe the buckling will be used by the one degree of freedom that characterizes the deviation of the bar from the initial position at the buckling.

We assume that the stiffness's in the nodes are different $\mathrm{k}_{1} \geq \mathrm{k}_{2}$, and then the critical values of the data's in the nodes also differ $\Delta_{1 \mathrm{c}} \leq \Delta_{2 \mathrm{c}}$. Longitudinal movements of the system will first be done at the expense of a node with less rigidity (the second node with the rigidity of the springs $\mathrm{k}_{2}$ ).

After the second elastic hinge flexibility is exhausted $\Delta_{2 \mathrm{c}}$ either stability may be lost, or the second node will begin to deform.
The displacements of the critical force $F_{c r}$ will not be greater $\Delta_{1 \mathrm{c}}$ and (or) $\Delta_{2 \mathrm{c}}$, plus transpositions due to the angle of deviation from the vertical. In what follows, we assume that the loss of stability at the nodes leads to a deviation of the second and the first rod in different directions.

\section{TIMOSHENKO CRITERION}

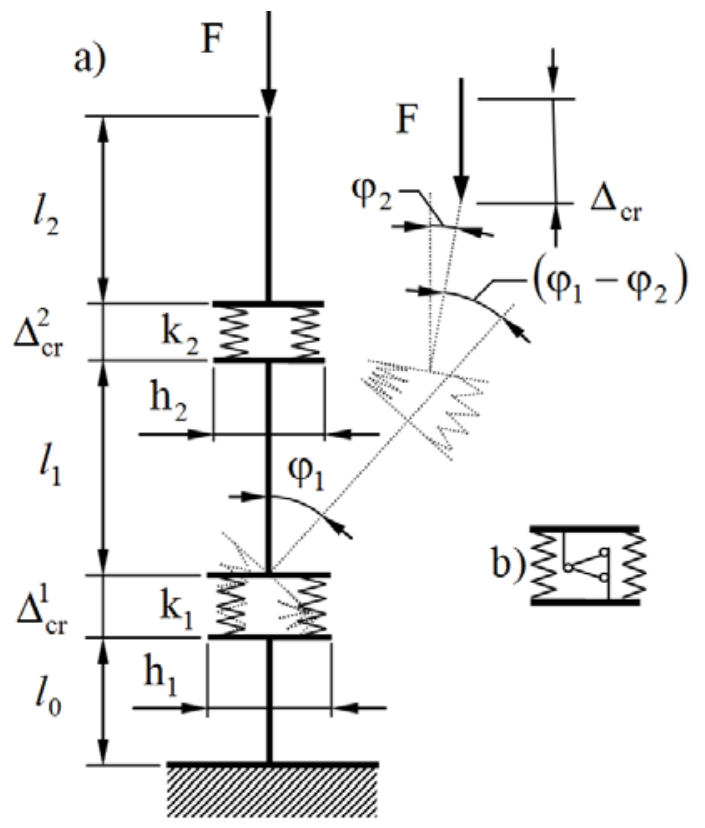

Figure 1: a) deformable system model; b) elastic hinge model

Let us consider an elastically deformable system subjected to direct compression shown in Figure 1. Following the Timoshenko's criteria, we neglect the phase of the energy accumulation by the system. We consider the moment of the system initial deformation shape loss, i.e. a deviation from the rectilinear state. 
The external force $\mathrm{F}_{\mathrm{cr}}$ will do possible work when a system transits to a new deformed state.

$$
W_{e x}=F_{c r} \Delta
$$

where the displacement is defined through an infinitesimal angle of the rod displacement $\varphi$, as follows:

$$
\Delta_{\mathrm{c}}=l_{1} \frac{\varphi_{1}^{2}}{2}+l_{2} \frac{\left(\varphi_{1}-\varphi_{2}\right)^{2}}{2}
$$

The springs performed the real work of internal forces in the two elastic hinges to put the system into a new equilibrium state:

$$
W_{\text {in }}^{1}=-k_{1} h_{1}^{2} \frac{\varphi_{1}^{2}}{4}, W_{\text {in }}^{2}=-k_{2} h_{2}^{2} \frac{\varphi_{2}^{2}}{4}
$$

The total energy of the system can be written as follows:

$$
\Pi=\mathrm{F}_{\mathrm{cr}}\left[l_{1} \frac{\varphi_{1}^{2}}{2}+l_{2} \frac{\left(\varphi_{1}-\varphi_{2}\right)^{2}}{2}\right]-\mathrm{k}_{1} \mathrm{~h}_{1}^{2} \frac{\varphi_{1}^{2}}{4}-\mathrm{k}_{2} \mathrm{~h}_{2}^{2} \frac{\varphi_{2}^{2}}{4}
$$

The condition of the system total energy minimum for equilibrium state is as follows:

$$
\frac{\partial \Pi}{\partial \varphi_{i}}=0, i=1,2
$$

It leads to a system of two homogeneous equations whose non-trivial solution requires that the determinant composed of the coefficients of the unknown system

$$
\left|\begin{array}{cc}
2 \mathrm{~F}_{\mathrm{cr}}\left(\mathrm{l}_{1}+\mathrm{l}_{2}\right)-\mathrm{k}_{1} \mathrm{~h}_{1}^{2} & -2 \mathrm{~F}_{\mathrm{cr}} \mathrm{l}_{2} \\
-2 \mathrm{~F}_{\mathrm{cr}} \mathrm{l}_{2} & 2 \mathrm{~F}_{\mathrm{cr}} \mathrm{l}_{2}+\mathrm{k}_{2} \mathrm{~h}_{2}^{2}
\end{array}\right|=0
$$

The solution of the equation obtained after the of the determinant resolves gives the values of the critical loads

$$
\begin{aligned}
& F_{c r_{1,2}}=\frac{l_{2} k_{1} h_{1}^{2}-\left(l_{1}+l_{2}\right) k_{2} h_{2}^{2}}{\left.2\left(l_{1}+l_{2}\right) l_{2}-l_{1} l_{2}\right)} \pm \\
& \pm \sqrt{\left[\frac{l_{2} k_{1} h_{1}^{2}-\left(l_{1}+l_{2}\right) k_{2} h_{2}^{2}}{2\left(\left(l_{1}+l_{2}\right) l_{2}-l_{1} l_{2}\right)}\right]^{2}+\frac{\left.4\left(l_{1}+l_{2}\right) l_{2}-l_{1} l_{2}\right) k_{1} h_{1}^{2} k_{2} h_{2}^{2}}{\left.\left(l_{1}+l_{2}\right) l_{2}-l_{1} l_{2}\right)^{2}}}
\end{aligned}
$$

To compare the results, we select the data adopted in [18] in solving a similar problem for the classical model $\mathrm{k}_{1}=\mathrm{k} ; \mathrm{k}_{2}=2 \mathrm{k}, \mathrm{l}_{1}=1 ; \mathrm{l}_{2}=2 \mathrm{l}, \mathrm{h}_{1}=\mathrm{h}_{2}=\mathrm{h}$.

Then the values of the obtained critical loads completely coincide with the values obtained in [09].

$$
\mathrm{F}_{\mathrm{cr}_{1}}=2 \frac{\mathrm{kh}^{2}}{\mathrm{l}}, \mathrm{F}_{\mathrm{cr}_{2}}=-\frac{\mathrm{kh}^{2}}{\mathrm{l}}
$$

\section{BRYAN CRITERION}

When applying the Bryan criterion, the internal strain energy is examined. It is important to take into account the stage of deformation internal energy accumulation by elastic body when the system is being compressed.
We will assume that the displacement in the first elastic hinge of the node depends on the difference of the angles of rotation $\varphi_{2}$

$$
\Delta_{1}=1_{1}\left(1-\cos \left(\varphi_{1}-\varphi_{2}\right)\right.
$$

In the second (upper node), the movement depends on the angle of rotation

$$
\Delta_{2}=1_{2}\left(1-\cos \varphi_{2}\right)
$$

We neglect the change in the longitudinal forces after the loss of stability and write down the expression for the possible work done by the minimum, from the critical forces arising in the elastic joints.

$$
\mathrm{W}_{\mathrm{in}}^{\mathrm{N}}=\mathrm{N}_{\mathrm{cr}} \Delta_{\text {lcr }}+\mathrm{N}_{\mathrm{cr}} \Delta_{2 \mathrm{cr}}
$$

The actual work of internal forces to bring the system to a new equilibrium state by rotation is defined as

$$
\mathrm{W}_{\text {in }}=2 \mathrm{k}_{1} \mathrm{~h}_{1}^{2}\left(\cos \frac{\varphi_{1}}{2}-1\right)+2 \mathrm{k}_{2} \mathrm{~h}_{2}^{2}\left(\cos \frac{\left(\varphi_{1}-\varphi_{2}\right)}{2}-1\right)
$$

The change in the internal potential energy has the form

$$
\begin{aligned}
& U=N_{c r} l_{1} 2 \sin ^{2}\left(\frac{\varphi_{1}-\varphi_{2}}{2}\right)+N_{c r} l_{2} 2 \sin ^{2}\left(\frac{\varphi_{2}}{2}\right)- \\
& -4 k_{1} h_{1}^{2} \sin ^{2}\left(\frac{\varphi_{1}}{4}\right)-4 k_{2} h_{2}^{2} \sin ^{2}\left(\frac{\varphi_{2}}{4}\right)
\end{aligned}
$$

The condition of stationary energy can be presented as follows:

$$
\frac{\partial \mathrm{U}}{\partial \varphi_{i}}=0, i=1,2
$$

We obtain a system of homogeneous nonlinear equations

$$
\begin{aligned}
& N_{c r} 1_{1} \sin \varphi_{1}-k_{1} h_{1}^{2} \sin \frac{\varphi_{1}}{2}-k_{2} h_{2}^{2} \sin \frac{\varphi_{1}-\varphi_{2}}{2}=0 \\
& N_{c r} 1_{2} \sin \varphi_{2}+k_{2} h_{2}^{2} \sin \frac{\varphi_{1}-\varphi_{2}}{2}=0
\end{aligned}
$$

Since the Brian criterion makes it possible to investigate the finite small translations of the system near the equilibrium state, one can take the sinus of the angles to be equal to the angles of rotation. The linearization of system equations (15) leads to a system of equations

$$
\left.\begin{array}{l}
\left(\mathrm{N}_{\mathrm{cr}}\left(\mathrm{l}_{1}+\mathrm{l}_{2}\right)-\mathrm{k}_{1} \mathrm{~h}_{1}^{2} / 2\right) \varphi_{1}-\mathrm{N}_{\mathrm{cr}} \mathrm{l}_{2} \varphi_{2}=0 \\
-\mathrm{N}_{\mathrm{cr}} 1_{2} \varphi_{1}+\left(\mathrm{N}_{\mathrm{cr}} \mathrm{l}_{2}+\mathrm{k}_{2} \mathrm{~h}_{2}^{2} / 2\right) \varphi_{2}=0 .
\end{array}\right\}
$$

The determinant composed of the coefficients of unknowns will have the form

$$
\left|\begin{array}{cc}
2 \mathrm{~N}_{\mathrm{cr}}\left(\mathrm{l}_{1}+\mathrm{l}_{2}\right)-\mathrm{k}_{1} \mathrm{~h}_{1}^{2} & -2 \mathrm{~N}_{\mathrm{cr}} \mathrm{l}_{2} \\
-2 \mathrm{~N}_{\mathrm{cr}} \mathrm{l}_{2} & 2 \mathrm{~N}_{\mathrm{cr}} \mathrm{l}_{2}+\mathrm{k}_{2} \mathrm{~h}_{2}^{2}
\end{array}\right|=0
$$


Calculating the determinant, we obtain expressions of internal critical forces that coincide with the expressions for the critical loads obtained for the received values of the system parameters (8)

$$
\mathrm{N}_{\mathrm{cr}_{1}}=2 \frac{\mathrm{kh}^{2}}{1}, \mathrm{~N}_{\mathrm{cr}_{2}}=-\frac{\mathrm{kh}^{2}}{1}
$$

The critical force value is identical to the critical load obtained in $[01,09]$, despite the differences in the physical models of the rods. This is because Brian criterion investigates the system close to the critical equilibrium position in the same way as Timoshenko criterion does.

But Timoshenko's criterion does not allow us to find the displacements received by the system at the moment of loss of stability. The Bryan criterion gives an opportunity to calculate the displacements, since it takes into account the stage of energy storage until the loss of stability.

We find the displacement of the system corresponding to the minimum value of the critical force, equating the actual work of the two compressible springs and the actual work of the longitudinal force reaching the critical value

$$
2 k_{1} \Delta_{c r}{ }^{2} / 2+2 k_{2} \Delta_{c r}{ }^{2} / 2=N_{c r} \Delta_{c r} / 2
$$

Taking into account the expression for the minimum critical force (18), we obtain

$$
\Delta_{\mathrm{cr}}=\frac{\mathrm{h}^{2}}{61}
$$

\section{THE CRITERION OF THE CRITICAL LEVELS OF ENERGY}

The condition of self-equilibrated state of the system can be represented as the difference of the work of internal forces maintaining this state in the system:

$$
\mathrm{W}_{\text {in }}=\mathrm{W}_{\text {in }}^{\mathrm{N}}-\mathrm{W}_{\mathrm{in}}^{\varphi} \rightarrow \min
$$

The possible work of longitudinal force, perfect to the appearance of a self-balanced state, can be represented in the form

$$
\mathrm{W}_{\mathrm{in}}^{\mathrm{N}}=\mathrm{N}_{\mathrm{cr}} \Delta_{\text {lcr }}+\mathrm{N}_{\mathrm{cr}} \Delta_{2 \mathrm{cr}}
$$

The work done by the springs on transferring the system to a new equilibrium state will be written as

$$
\mathrm{W}_{\text {in }}^{\varphi}=\frac{\varphi^{2}{ }_{1}}{2} \mathrm{k}_{1} \mathrm{~h}_{1}^{2}+\frac{\left(\varphi_{1}-\varphi_{2}\right)^{2}}{2} \mathrm{k}_{2} \mathrm{~h}_{2}^{2}
$$

We take dimensionless variables, as in (16)

$$
\begin{aligned}
& \bar{\Delta}_{1 c}=\frac{\Delta_{1 c}}{l}, \bar{\Delta}_{2 c}=\frac{\Delta_{2 c}}{l}, \bar{W}_{i n}^{\varphi}=\frac{W_{i n}^{\varphi}}{k l^{2}}, \bar{W}_{i n}^{N}=\frac{W_{i n}^{N}}{k l^{2}}, \\
& \bar{N}_{c r}^{1}=\frac{N_{c r}^{1}}{k l}, \bar{N}_{c r}^{1}=\frac{N_{c r}^{1}}{k l}, \bar{k}_{1}=\frac{k_{1}}{k}, \bar{k}_{2}=\frac{k_{2}}{k}, \\
& \bar{h}_{1}=\frac{h_{1}}{l}, \bar{h}_{2}=\frac{h_{2}}{l}, \bar{l}_{1}=\frac{l_{1}}{l}, \bar{l}_{2}=\frac{l_{2}}{l}
\end{aligned}
$$

The condition for the normalization of displacements is written in the form

$$
\bar{\Delta}_{\mathrm{lcr}}{ }^{2}+\varphi_{1_{\mathrm{cr}}}^{2}+\bar{\Delta}_{2 \mathrm{cr}}{ }^{2}+\varphi_{2 \mathrm{cr}}{ }^{2}=1
$$

The Lagrange equation for the problem posed will have the form

$$
\begin{aligned}
& L=\bar{N}_{c r} \bar{l}_{1} \frac{\left(\varphi_{1}-\varphi_{2}\right)^{2}}{2}+\bar{N}_{c r} \bar{l}_{2} \frac{\varphi_{2}^{2}}{2}--\bar{k}_{1} \bar{h}_{1}^{2} \frac{\varphi_{1}^{2}}{4}-\bar{k}_{2} \bar{h}_{2}^{2} \frac{\varphi_{2}^{2}}{4} \cdot+ \\
& \left.+\lambda \bar{\Delta}_{1 c r}{ }^{2}+\varphi_{1 c r}^{2}+\bar{\Delta}_{2 c r}{ }^{2}+\varphi_{2 c r}^{2}-1\right)
\end{aligned}
$$

The stationarity condition for the Lagrangian with respect to the variables leads to a system of equations

$$
\frac{\partial L}{\partial \varphi_{1 c r}}=0, \quad \frac{\partial L}{\partial \varphi_{2 c r}}=0
$$

We obtain the eigenvalue problem of the form

$$
[\mathrm{K}]\left\{\varphi_{\text {icr }}\right\}=[\lambda]\left\{\varphi_{\text {icr }}\right\}
$$

Where the state matrix of the system is

$$
[\mathrm{K}]=\left|\begin{array}{cc}
\overline{\mathrm{N}}_{\mathrm{cr}}\left(\overline{\mathrm{l}}_{1}+\overline{\mathrm{l}}_{2}\right)-\overline{\mathrm{k}}_{1} \overline{\mathrm{h}}_{1}^{2} / 2 & -\overline{\mathrm{N}}_{\mathrm{cr}} \overline{\mathrm{l}}_{2} \\
-\overline{\mathrm{N}}_{\mathrm{cr}} \overline{\mathrm{l}}_{2} & \left(\overline{\mathrm{N}}_{\mathrm{cr}} \overline{\mathrm{l}}_{2}+\overline{\mathrm{k}}_{2} \overline{\mathrm{h}}_{2}^{2} / 2\right.
\end{array}\right|
$$

Eigenvector are

$$
\left\{\varphi_{\text {icr }}\right\}=\left\{\varphi_{1 \mathrm{cr}}, \varphi_{2 \mathrm{cr}}\right\}^{\mathrm{T}}=\left\{\frac{\mathrm{h}^{2}}{31}, \frac{\mathrm{h}^{2}}{61}\right\}^{\mathrm{T}}
$$

Eigenvalue are

$$
[\lambda]=\left|\begin{array}{cc}
2 \frac{\mathrm{kh}^{2}}{1} & 0 \\
0 & -\frac{\mathrm{kh}^{2}}{1}
\end{array}\right|
$$

We obtained results that coincide with the results of the previous sections, since the system was investigated near the equilibrium state for small deviations from it. 


\section{CONCLUSIONS}

The energy criterion in the form of Timoshenko explores the system near the initial equilibrium state, assuming infinite deformations and deviations from the initial equilibrium state. As a result, it does not allow us to estimate the displacements of the system at the time of loss of stability and take into account other important properties of elastic systems [9]. However, the method is simple, and is obvious both in the formulation of the problem, and in its mathematical formulation, in estimating the value of the critical load.

The energy criterion in the form of Brian is valid for conservative systems and takes into account the history of deformation.

The formulation of the problem allows us to take into account small finite displacements, and the recording of the energy relationships does not depend on the type of external load applied, which in a number of problems gives significant advantages [09]. From these relations follows the periodic regularity of the critical parameters of the system.

Criterion of critical energy levels in its formulation is based on a hypothesis about the existence of critical levels of internal energy of a structure and the periodicity of its properties. Limitations in the form of a normalization condition allow us to consider finite values of design parameters. The most general record of energy in the form of a condition of a minimum of internal energy with constraints on the design parameters, corresponding to the state of self-equilibrium of the system, neither makes it possible to depend on the path of deformation nor on the type applied to the load. The requirement of conservatism of the system is preserved.

\section{REFERENCES}

1. Timoshenko S.P. Ustoichivost uprugikh sistem. Moscow, OGIS, 1946. p 532

2. Bryan G. H., On the Stability of a Plane Plate Under Thrusts in Its Own Plane, with Applications to the 'Buckling' of the Sides of a Ship//Proc. London Math. Soc., 1891. Vol. 22.

3. Rzhanizin A.R.. Ustoichivost ravnovesiya uprugih sistem. Moscow, Gostehizdat. 1955. p 475

4. Bolotin V.V. Dinamicheskaya ustoichivost uprugikh sistem. Moscow, Gostehteorizdat, 1956. p 600

5. Volmir A.S. Ustoichivost uprugikh sistem. Moscow, Fizmatgiz, 1963. p 879

6. Panovko Ya.G., Gubanova I.I. Ustoichivost i kolebaniya uprugikh sistem: Sovremennye konsepsii, oshibki i paradoksiy. Moscow, Nauka, 1979. p.384

7. L.U. Stupishin, K.E. Nikitin Investigation of the shell's stability using the mixed finite element method //Advances in Civil, Architectural, Structural and Constructional Engineering - Kim, Jung \& Seo (Eds) (C) 2016 Taylor \& Francis Group, London.

8. Stupishin L.U. Variational Criteria for Critical Levels of Internal Energy of a Deformable Solids //Applied Mechanics and Materials Vols. 578-579 (2014) pp 1584-1587

9. Alfutov N.A. Osnovy rascheta na ustoichivost uprugih sistem Moscow, Mashinostroenie. 1991 p 336 